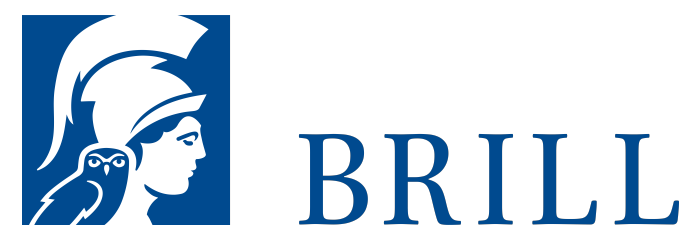

\title{
Ein Vorläuferstadium des Zählens und Abstrahierens bei "Homo erectus"
}

Die Knochen-Artefakte von Bilzingsleben gedeutet als der Menschheit früheste Aufzeichnungen von Mondbeobachtungen

\section{Author: Theodor Schmidt-Kaler}

Die Nordrhein-Westfälische Akademie der Wissenschaften und der Künste ist eine Vereinigung der führenden Forscherinnen und Forscher des Landes. Sie wurde 1970 als Nachfolgeeinrichtung der Arbeitsgemeinschaft für Forschung des Landes Nordrhein-Westfalen gegründet. Die Akademie ist in drei wissenschaftliche Klassen für Geisteswissenschaften, für Naturwissenschaften und Medizin sowie für Ingenieur- und Wirtschaftswissenschaften und in eine Klasse der Künste gegliedert.

Mit Publikationen zu den wissenschaftlichen Vorträgen in den Klassensitzungen, zu öffentlichen Veranstaltungen und Symposien will die Akademie die Fach- und allgemeine Öffentlichkeit über die Arbeiten der Akademie und ihrer Forschungsstellen informieren.

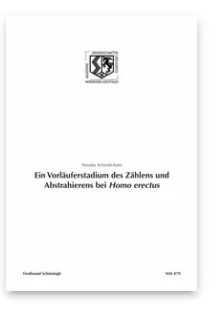

Pages: 47 Seiten, $6 \mathrm{~s} / \mathrm{w}$ und 3 farb. Abb., 2 s/w Tab.

Language:

German

Subjects:

Archaeology, Art

\& Architecture,

Classical Studies

Publisher: Brill |

Schöningh

Series:

Nordrhein-

Westfälische

Akademie der

Wissenschaften und der Künste -

Naturwissenschaften und Medizin,

Volume: 479

E-Book (PDF)

Released online: 29 Oct 2019

ISBN: 978-3-

657-77389-3

List price

Paperback

Publication date:

$16 \mathrm{Jul} 2012$

ISBN: 978-3-

506-77389-o

List price 
For more information see brill.com

Order information: Order online at brill.com +44330 333 0049 | customerservices@brill.com Submission information: brill.com/authors

Titles published by Brill | Fink, Brill | mentis or Brill | Schöningh: +49(o)715413279216| brill@brocom.de 